\title{
The Impact of Experience and Technology Change on Task-Technology Fit of a Collaborative Technology
}

\author{
Jakob H. Iversen ${ }^{1} \&$ Michael A. Eierman ${ }^{1}$ \\ ${ }^{1}$ College of Business, University of Wisconsin Oshkosh, Oshkosh, Wisconsin, USA \\ Correspondence: Jakob H. Iversen, College of Business, University of Wisconsin Oshkosh, Oshkosh, Wisconsin, \\ USA. Tel: 1-920-424-4151.
}

Received: January 2, 2018

Accepted: January 30, 2018 Online Published: March 8, 2018

doi:10.5539/jel.v7n3p56

URL: https://doi.org/10.5539/jel.v7n3p56

\begin{abstract}
This study continues a long running effort to examine collaborative writing and editing tools and the factors that impact Task-Technology Fit and Technology Acceptance. Previous studies found that MS Word/email performed better than technologies such as Twiki, Google Docs, and Office Live. The current study seeks to examine specifically the impact of experience on these outcomes. Fortuitously, during the course of the study, Office Live was redesigned and renamed as Office 365, thus also allowing the examination of tool characteristics. In contrast to previous studies, Google Docs and Office 365 now performed significantly better than MS Word/email on the outcome measures despite users having significantly more experience with the latter. We speculate that as users gain experience with tools that perform the collaborative writing and editing task differently than did past tools, they perceive that the old technology no longer fits the task as well and thus it performs lower on outcome measures. We also observed that even though the Word/email technology did not change during the time of the study, its scores went down, possibly due to users' experience with newer technologies more suited to the task.
\end{abstract}

Keywords: collaboration, collaborative writing, e-collaboration, wiki, word processing, Google Docs, Office Live, Office 365, task-technology fit (TTF), technology acceptance model (TAM)

\section{Introduction}

This study continues an exploration by the authors of the factors that impact collaborative document creation and editing (Dishaw, Eierman, Iversen, \& Philip, 2011, 2013). The study is important because on-line collaboration is becoming increasingly important to the function of organizations (Frost \& Sullivan, 2006; Hertel, Geister, \& Konradt, 2005) and is increasingly used in education (Brodahl, Hadjerrouit, \& Hansen, 2011; Parker \& Chao, 2007). Our previous studies used the TAM/TTF model (Dishaw \& Strong, 1999) and a set of challenges for e-collaboration identified by Nosek \& McManus (2008) as theoretical underpinnings to evaluate the studies' outcomes.

In the first study, we compared a collaborative task performed by virtual teams using Twiki (a version of a wiki) with the same task and virtual teams using a combination of Microsoft Word and email (Dishaw et al., 2011). Virtual teams consisted of undergraduate students working in groups of three completed the project. The results from 552 undergraduate students found that:

- The perceived effort required to collaborate on the project was similar for the groups using Word/email and the groups using Twiki.

- Task-Technology Fit was perceived to be better by the students using Word/email than the students using Twiki.

- Students perceived Word/email to be more useful than Twiki.

- $\quad$ Students perceived Word/ email to be easier to use than Twiki.

Because the Twiki tool was designed to support collaborative work, while Word and email were adopted to support the collaborative task, it was somewhat surprising that the first three results showed that Word/email outperformed Twiki. It was not surprising to find that Word/email was easier to use. The Twiki tool had a relatively simple editing interface, typical of web editors of the time, whereas Word was a fully functional word 
processing system. Overall, our conclusion was that "there currently is no advantage for students in using wiki technology in a collaborative writing assignment" (Dishaw et al., 2011, p. 51). While this conclusion is interesting, it does not answer why these results were observed. The challenges to effective e-collaboration identified by Nosek \& McManus (2008) are a possible explanation for the findings. Three of the five challenges stand out as potential explanations: 1) the cognitive model of group process, 2) the conceptual (mental) model of performing the collaborative task, and 3) technical challenges associated with using the technology.

To understand these results the study was repeated with two additional technologies: Google Docs and Office Live (since renamed to Office 365) (Dishaw et al., 2013). The two new technologies were included because they implement the support of collaborative writing and editing in a different manner than either Wiki or Word/email. This difference was thought would help explain why the previous results were observed. Google Docs was included to contrast with Twiki. In both technologies, there is the same central collaboration model in that all users work on the exact same item. However, in Twiki there isn't a notion of a traditional document-instead, the users build a website consisting of multiple inter-linked pages. Google Docs employs a document-based model similar to MS Word. Office Live, which uses MS Word (or its web-based equivalent) as the editor, was included because, enables a comparison with a rich editor like MS Word, but with a different collaboration model using a single, central document repository in the cloud.

Our 2013 study included the data from the previous study and added 282 data points from students using Office Live and Google Docs. That study had the following findings:

- Task-Technology Fit: Word/email and Google Docs were perceived to have a better Task-Technology Fit than Twiki or Office Live with no perceived difference in fit between Word/email and Google Docs or between Twiki and Office Live.

- Usefulness: Word/email was perceived to be more useful than any of the other technologies followed by Google Docs. We found no perceived difference in usefulness between Twiki and Office Live.

- Ease of Use: Word/email was perceived to be easier to use than any of the other technologies followed by Google Docs. We found no perceived difference in perceived ease of use between Twiki and Office Live.

- Effort to Collaborate: The effort to collaborate was perceived to be significantly higher with Office Live than with any of the other technologies. We found no difference in perceived effort to collaborate between Word/email, Google Docs, and Twiki.

These results were evaluated using the TAM/TTF model and the e-collaboration challenges identified by Nosek $\&$ McManus (2008) to understand why they occurred. We proposed three possible explanations for these results. First, Office Live's poor showing is explained by Nosek \& McManus (2008) e-collaboration challenge: conceptual (mental) model of performing the collaborative task. Office Live did not work as expected, and thus violated the user's mental model of the task. Second, MS Word/email performed better than the other technologies due to user experience, as predicted by the TAM/TTF model. User experience with MS Word/email is much higher than with the other technologies. Finally, to explain Google Docs' performance being close to that of MS Word/email, we postulated a "Compensatory Factor." Essentially, the explanation is that even though Word has a better editor, Docs has better support for collaboration; thus, they scored essentially the same on the TTF variables. However, because more time was spent writing and editing than collaborating, the outcome variables were impacted in favor of Word/email.

In the study at hand, we continue to explore these issues. This study was originally designed to specifically examine the role Tool Experience had on the outcomes of the second study. As luck would have it, during the three semesters that data was collected, Office Live had a complete renovation and became Office 365 . This added the dimension of a change in Tool Functionality and enhanced the study's ability to gain insight into what was causing the results we were seeing.

\section{Theoretical Background}

\subsection{TAM/TTF Model}

This study uses the TAM/TTF model (Dishaw \& Strong, 1999), the e-collaboration challenges identified by Nosek \& McManus (2008), and our previous results as the theoretical basis for this examination. The TAM/TTF model (Figure 1) is a well-established extension to Technology Acceptance Model (TAM) (Davis, Bagozzi, \& Warshaw, 1992; Venkatesh \& Davis, 2000) and the Task-Technology Fit model (TTF) (Goodhue \& Thompson, 1995) that has more explanatory power than either model alone (Dishaw \& Strong, 1999) and has been used in over 100 studies to examine technology acceptance in a variety of settings. The TAM/TTF model suggests not only that ease of use and usefulness indirectly impact acceptance of a tool, but also that ease of use and 
usefulness are impacted by the fit between the technology and the task, and that this fit also directly impacts acceptance (actual tool use in the model). This model also considers the effect of the user's experience with the tool on perceived ease of use and usefulness.

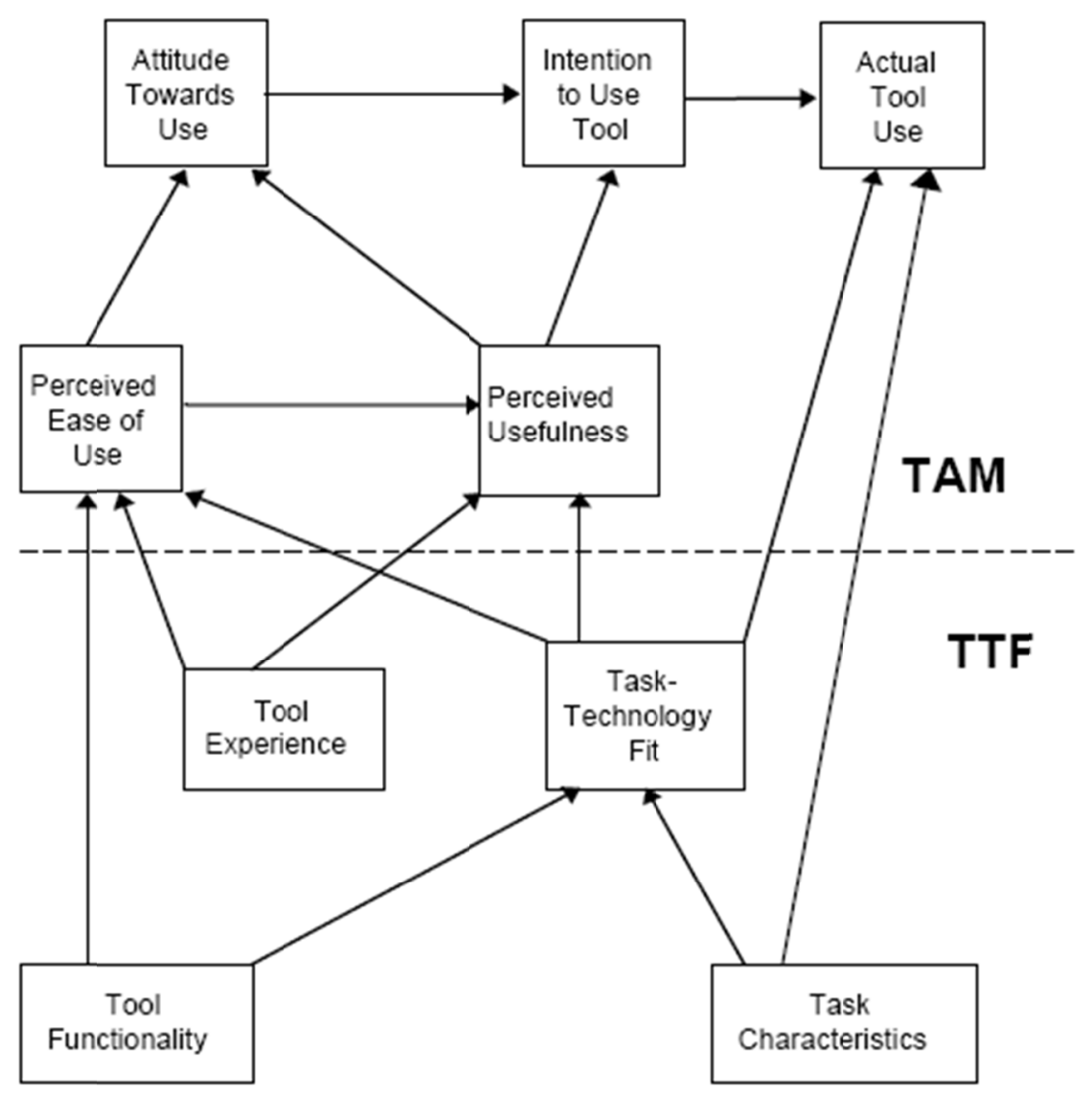

Figure 1. Combined TAM/TTF model

\subsection{Challenges of E-Collaboration}

Previous research suggests that collaborative technologies are not as effective as they might be due to some challenges facing e-collaboration (Nosek \& McManus, 2008). The challenges identified include: 1) group process challenges, 2) theoretical challenges that limit the scope of work and new conceptualizations, 3) conceptual challenges that affect what individuals conceive of doing with the technology, 4) technical challenges that limit what the technology can do, and 5) use challenges that suggest usefulness is the only predictor for continued acceptance and use of a technology (Kock, 2005; Nosek \& McManus, 2008). These challenges are examined through a series of studies to attempt to understand if task-technology fit theory applies to collaborative technology and which of these impacts the fit of the technology to the task.

\subsection{Application of Task-Technology Fit to Collaborative Technology}

Our previous studies added to the body of literature that shows better Task-Technology Fit is associated with better perceptions of ease of use and usefulness of a technology. The studies then used Nosek and McManus (2008) to attempt to explain why one technology has a better fit than another. Our first study (Dishaw et al., 2011) suggested that three e-collaboration challenges identified by Nosek \& McManus (2008) stood out as potential explanations for the finding that Twiki was not perceived to support the collaborative task as well as MS Word/email: 1) the cognitive model of group process, 2) the conceptual (mental) model of performing the collaborative task, and 3) technical challenges associated with using the technology.

That study occurred prior to development and widespread use of technologies like Google Docs. At that time, collaboration on writing and editing papers using word processing software and sharing the paper via email was 
the norm and students likely developed a cognitive model of group processes that revolved around using these technologies. However, using a wiki required a change in that process due to its different implementation of the document and sharing. The forced adaptation of wiki and associated process likely caused challenges that are reflected in students' perceptions of the usefulness and ease of use of the tool.

\subsubsection{Mental Model}

The students' conceptual or mental model of the writing/editing task may be an important explanation. Students likely developed a strong mental model of how to use word processing software in the writing/editing task because they have had a lot of experience doing it. Twiki's editing interface is different and its capabilities are much less sophisticated than Word's even though it provides many of the same features. While students received instruction on the use of Twiki, the different mental model it required may have led to the perceptions of lower usefulness and ease of use.

\subsubsection{Technical Challenges}

Technical challenges associated with using Twiki provided a final potential explanation for its lower perceptions of usefulness and ease of use. Garza and Kock (2007) suggest that quality of a collaboration technology's interface plays a key role in the success of the technology. Twiki does not have a sophisticated interface with the same power as the word processing software. Tracking changes is also more difficult and confusing in Twiki than MS Word. This requires reviewing a history of different versions in different windows rather than a marked up single document. Finally, the Twiki procedure for controlling access to a document is both difficult and unreliable whereas a Word document is inherently unavailable to others. On the other hand, the history function of Twiki is far more robust than in Word, as Twiki reliably keeps every version of the document, and students reported anecdotally that they found it very useful to be able to see who had made recent changes to the document. However, taken together, these issues may contribute to lower perceptions of the Twiki collaboration technology.

\subsection{The Dimensions of Technology that Impact Fit}

In the second study, (Dishaw et al., 2013) we included Google Docs and Office Live to contrast the Word/email and Twiki technologies because it allowed us to compare four technologies along three dimensions: perceived document location, perceived document model, and editor quality/richness (Figure 2).

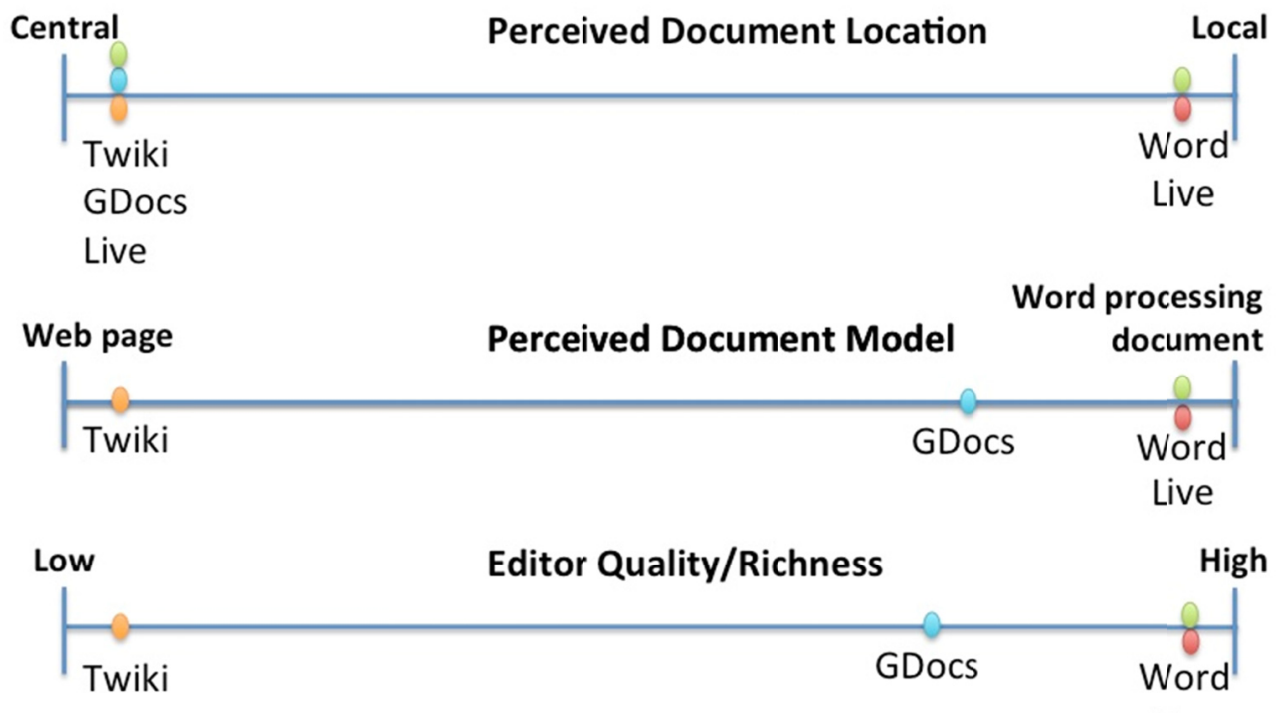

Figure 2. Technologies arranged along three dimensions

The second study found that MS Word/email was perceived to be the best technology with respect to perceived ease of use and perceived usefulness, with Google Docs a close, but statistically significantly, second. Office Live and Twiki had significantly lower scores that were not much different from one another. 
MS Word/email did not differ from Google Docs in Task-Technology Fit, and both Office Live and Twiki had fit measures significantly lower than the other two. As in perceived ease of use and usefulness, Office Live and Twiki were not much different in Task-Technology Fit. The interesting thing about these results is the performance of Office Live, given that it is quite close to MS Word/email on the three dimensions thought to impact fit and that Google Docs performed worse than MS Word/email on Perceived Ease of Use and Perceived Usefulness, although they were rated the same in Task-Technology Fit.

\subsection{The Role of Experience}

One explanation for these results is experience with the tool. Students probably have more experience with MS Word/email than Google Docs, and more experience with both of these tools than Office Live. The TAM/TTF model (Figure 1) shows that Tool Experience impacts Perceived Ease of Use and Perceived Usefulness, so that could be the explanation. In the study at hand, we collected data on tool experience that showed that students, in general, had significantly more experience with Word/email than any of the other technologies. Unfortunately, in previous studies, we did not collect experience at the same time or with the same students, so although suggestive, this is not a definitive result.

\subsection{Compensatory Factors}

Another explanation for the distinction between Word/email and Google Docs was developed based on the technology dimensions identified in Figure 2. This explanation was termed the "Compensatory Factor." Essentially, the explanation is that Word has a better editor, but Google Docs has better support for collaboration; thus, they scored essentially the same on the TTF variables. However, because more time was spent writing and editing than on collaborating, the outcome variables were impacted in favor of Word/email.

\subsection{The Uncanny Valley}

The explanation offered for Office Live's unexpectedly poor performance is that it violated the students' mental model of how the tool should work. Rienzo \& Han (2009) found that students preferred the writing and editing capabilities and familiarity of Office Live to Google Docs, but preferred Google Docs' real-time editing capability to Office Live's. This supports the notion that the issue is not with the editing capability, but with the mental model of either collaboration, the location of the document, or both. When using Word/email, the process of collaboration may be cumbersome, but the process is familiar, and it is obvious what is going on. In Office Live, the collaboration process is more obscure. It requires setting up collaboration on a website, and then the collaboration happens only through the Save/Refresh button. It is the Save/Refresh button that produces the confusion. Office Live stores its documents stored centrally, and the user no longer has to manage documents as files. Changes made by a user are not visible to another concurrent user until the document is "saved" by both. This may lead to confusion for inexperienced users on the mental model of where the document is stored and what the latest version is, potentially leading to a frustrating experience and even data loss.

The Word interface in Office Live is almost identical to the regular interface. The only difference is that the Save button has been replaced with a Refresh button that while looking almost identical (Figure 3), has a very different function. Pressing the Save button in Word simply writes the current document to a file. Pressing the Refresh button in Office Live saves the document but also pulls the changes made by other collaborators and shows those on the screen thus leading to confusion as to whether the document was saved or not.
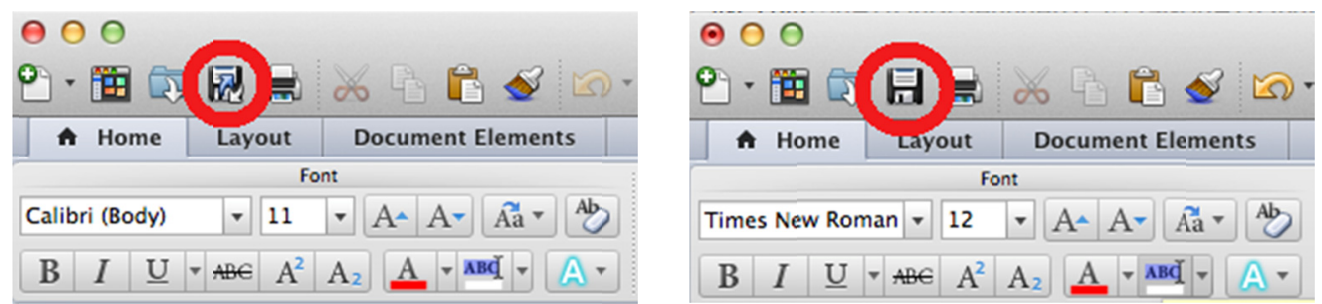

Figure 3. Difference in user interface between office live document in word (left) and word (right)

This difference likely causes confusion for the users because it violates their mental model of what the Save button does. This, in turn, led to the lower ratings for fit and Perceived Ease of Use and Perceived Usefulness. This explanation was termed the "Uncanny Valley" because of its similarity to the effect experienced in robotics 
where the positive response to a humanoid dramatically decreases if the robot is too close to being human, but not close enough to completely fool the individual (Mori, 1970).

In the current study, we examine these explanations by measuring Tool Experience. The TAM/TTF model suggests experience impacts Perceived Ease of Use and Perceived Usefulness directly, which could explain the difference seen between Google Docs and MS Word/email, but we postulate that experience also could impact perceptions of Task-Technology Fit because it changes the user's mental model of the way the technology works (Nosek \& McManus, 2008). Dishaw \& Strong (2003) found that tool experience, as a moderating variable on Task-Technology fit, adds explanatory power to the model. During data collection, Office Live went through a transformation to Office 365 , giving us an opportunity to also examine the impact of this functionality change.

\section{Research Model}

This study uses an adaptation of the combined TAM/TTF model (Figure 4) developed by the authors (2011) and modified based on Dishaw \& Strong $(1999,2003)$ to examine the research question:

How does tool functionality and tool experience impact user perceptions of the usefulness and ease of use of collaborative tools?

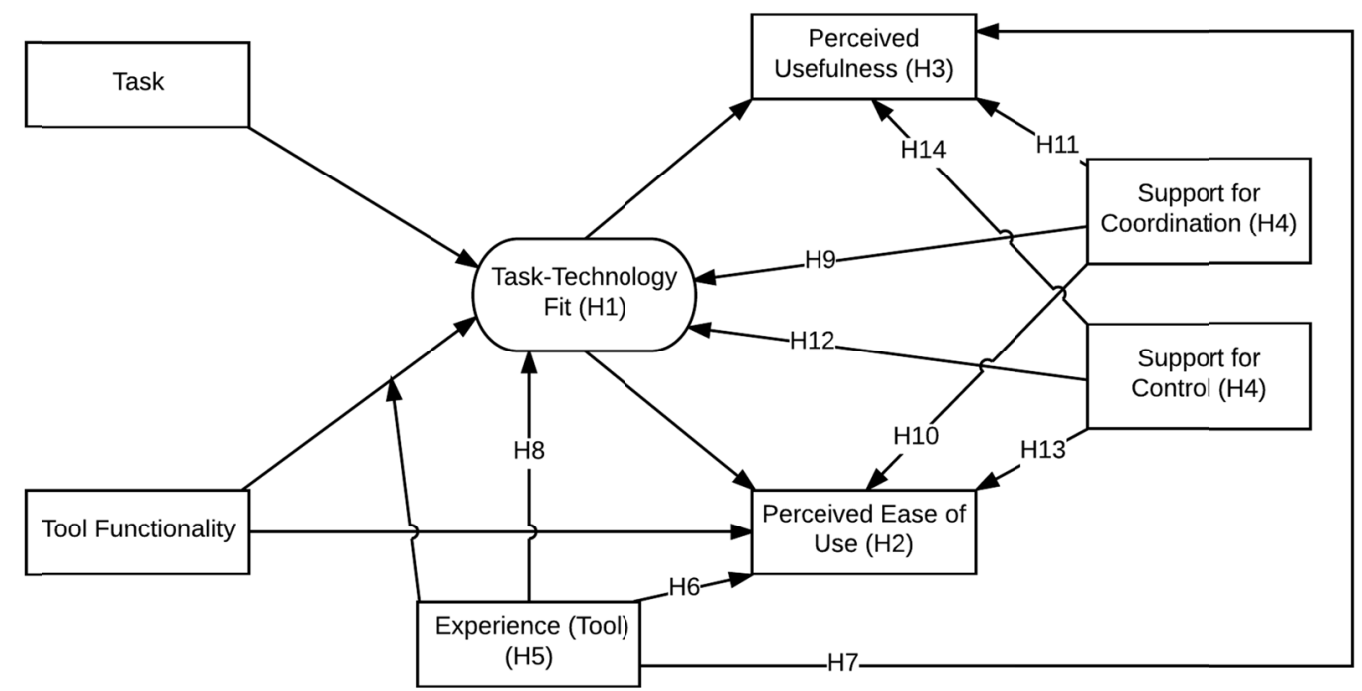

Figure 4. Research model

The dependent variables measured are the TAM variables Perceived Ease of Use and Perceived Usefulness. The independent variables measured are the TTF variables Task Characteristics, Tool Functionality, and Tool Experience. The task characteristics variable is held constant across treatments by assigning all subjects the same task (to write a group paper). Tool Functionality is varied between subjects. There are three treatment groups based on the tool used: MS Word Documents exchanged via email, Office Live/Office 365, and Google Docs. We also used Coordination and Control as independent variables. While these measures are dependent on the degree to which the tool's functionality impacts the subjects' perceptions of their ability to coordinate their work with other group members and the degree to which the tool's functionality enforced control on their work on the collaboration, they also may impact the subjects' perception of the dependent variables. Perceived Ease of Use, Perceived Usefulness, Coordination and Control are measured using an instrument previously developed by Dishaw \& Strong (1999). Tool experience is measured via a survey (Appendix A).

The original studies included a wiki as a collaboration tool. However, both studies showed it to be inferior to other tools, and the advent of much more sophisticated tools such as Office 365 and Google Docs suggests that it will never perform as well, so it was eliminated from this study.

\section{Hypotheses}

In our two earlier studies (Dishaw et al., 2011, 2013), we determined that there was a difference in Task-Technology Fit, perceived ease of use, and perceived usefulness between the four tools investigated. In both studies, the MS Word/email tool was found to have better perceptions of ease of use than any of the other tools. The second study found that Office Live performed surprisingly poorly in all measures. The current study 
seeks to investigate these findings by measuring the subjects' experience with the tools and examining different tool functionality to determine which characteristics lead to a better fit with the task.

The first four hypotheses test whether or not there is a difference between the tools with respect to the dependent variables of Task-Technology Fit, Perceived Ease of Use, and Perceived Usefulness, and whether or not the tools differ in their perceived support of coordination and control. These hypotheses are the same as in the first two studies.

Hypothesis 1: There is no difference in Task-Technology Fit between the three tools.

Rejecting this hypothesis will suggest that one or more of the technologies is a better fit with the collaborative writing task than the others. A difference in fit by itself does not imply a "better fit." To examine the question of better fit, differences in the dependent variables Perceived Ease of Use and Perceived Usefulness need to be tested. If we determine there is a difference in these variables, a higher value will be interpreted to mean a "better fit."

The second and third hypotheses tests whether there is a difference in ease of use and usefulness between the tools.

Hypothesis 2: There is no difference in Perceived Ease of Use between the three tools.

Hypothesis 3: There is no difference in Perceived Usefulness between the three tools.

The fourth hypothesis tests for differences between the tool's impact on perceived support for collaboration and control. If there is a significant difference, a higher value will be interpreted to mean that more support is perceived. A difference in the perceived support may be an explanation for differences in Task-Technology Fit and the other outcome variables.

Hypothesis 4: There is no difference in perceived tool support for coordination and control between the three tools.

The second set of hypotheses examines the relationship between the independent variables (Tool Functionality and Tool Experience) and the dependent variables. Hypotheses 6, 7, and 8 focus on Tool Experience. In the first two studies, Word/email scored better on Perceived Ease of Use and Perceived Usefulness than any of the other technologies. This held true in the second study even when Task-Technology Fit was the same for Word/email and Google Docs. Furthermore, the very poor showing by Office Live could be due to a significant lack of experience with technology rather than the "Uncanny Valley."

Hypothesis 5: There are no differences in subjects' level of experience with the technology between the three tools.

Hypothesis 6: There is no correlation between tool experience and Perceived Ease of Use.

Hypothesis 7: There is no correlation between tool experience and Perceived Usefulness.

Hypothesis 8: There is no correlation between tool experience and Task-Technology Fit.

One of the explanations forwarded for the tie between Word/email and Google Docs in Task-Technology Fit but a difference in Perceived Ease of Use and Perceived Usefulness was that Google Docs provided better coordination support than Word/email, which compensated for its lower quality editing interface. Higher values on these measures is interpreted to mean strong support. A significant relationship along with higher values would substantiate this conclusion.

The following hypotheses (H9-H14) examine this relationship based on measurements of the tool's perceived support of coordination and control relative to Ease of Use, Usefulness, and Task-Technology Fit.

Hypothesis 9: There is no correlation between perceived support of Coordination and Task-Technology Fit.

Hypothesis 10: There is no correlation between perceived support of Coordination and Perceived Ease of Use.

Hypotheses 11: There is no correlation between perceived support of Coordination and Perceived Usefulness.

Hypothesis 12: There is no correlation between perceived support of Control and Task-Technology Fit.

Hypothesis 13: There is no correlation between perceived support of Control and Perceived Ease of Use.

Hypotheses 14: There is no correlation between perceived support of Control and Perceived Usefulness.

\section{Research Design and Methodology}

This study uses a field experiment to test the hypotheses. The study keeps the task constant and varies the technology by assigning a tool to each group of students. The subjects are students in different sections of the 
same course, all taught by the same instructor. All sections used the same task, and all subjects in a single section used the same tool. The tool was varied by section. Tools used were MS Word/email, Google Docs, and Office Live/Office 365. The unit of analysis is the individual subject participating in the task. Data is collected via survey at the end of the course.

This research project is based on teaching the course "Essentials of IS," which is required for all business majors in the College of Business at a Midwestern US university where the study took place. Data was collected in the Fall 2013, Spring 2014, and Fall 2014 semesters, with a total of 162 students participating in the study. All sections were taught face-to-face to a mostly traditional undergraduate college population (18-22-year olds) of full-time students originating from the local area (very few international students). The population is roughly equal in terms of gender. Most students take the course as sophomores and juniors (second and third year of college). Table 1 shows how many surveys were completed for each technology.

Students in sections assigned to use word processing and email were shown how to use the Track Changes feature of MS Word to help identify changes made by different group members. They were not given specific instructions on how to collaborate; however, they were asked to use email for communication and exchange of documents.

Table 1. Details of study

\begin{tabular}{ll}
\hline Technology & Responses \\
\hline Word+email & 44 \\
Google Docs & 83 \\
Office 365 & 35 \\
\hline
\end{tabular}

Because students are less familiar with Office Live/365 and Google Docs than with MS Word, detailed written instructions, as well as demonstrations, were given to students on the use of Office Live/365 and Google Docs. The instructions were given as part of the regular classroom teaching routine. All treatment groups were taught by the same instructor.

The collaboration project used for the research is the same as used in the previous studies. It is a group research paper where students in groups of three were asked to find and describe an emerging and/or disruptive information technology that would provide some competitive advantage to a fictitious company. The company varied by semester and included a small manufacturing firm (making wooden pallets), a regional hotel chain, and a small specialized retailer (selling snowboards and accessories). All students taking the course in one semester were given the same assignment regardless of the section or technology they were assigned. The core part of the assignment was for students to apply the value chain model as well as Porter's Five Forces Model to determine the technology's effects on the firm. Completed papers were typically 1,200 to 1,500 words in length.

Group membership was determined randomly by the instructor. Students were asked to avoid face-to-face meetings and were not given time in class to work on or coordinate the project. This was done to force students to experience how projects are conducted in organizations where participants may not see each other, and often live in different time zones, making real-time communication difficult. The varied schedules of students helped to make it naturally difficult for them to schedule real-time meetings. To ensure that students worked seriously on the assignment, the paper was a significant part of a student's overall course grade (approximately 20\%).

After the paper was turned in at the end of the semester, students were asked to fill out a web-based survey about their experience with the project. Students were given a small number of extra credit points to complete the survey. This resulted in a very high response rate, but because students were given the extra credit only after the project was graded, and they were clearly instructed that the specific answers given would in no way affect their grade, this should not affect the specific answers to questions. To reinforce this, students were given clear guarantees that their instructor would not be able to see their answers to any of the questions.

The online survey asked detailed questions about the participants' experience with collaboration on the project. The survey was based on the instrument developed by Dishaw \& Strong (1999) to integrate the Technology Acceptance Model (TAM) with Task-Technology Fit (TTF) concepts. The wording in the survey was adapted to fit the technology used in this study and task at hand (Appendix A includes the entire survey). The bulk of the survey is the same as the previous studies. However, a new section on tool experience was added to capture this dimension of the study. The survey results were anonymous, but students were sent individual links, allowing the 
survey tool to keep track of which students had completed the survey in order to facilitate awarding extra credit points and sending reminders to complete the survey.

While analyzing the results, incomplete surveys were discarded. The survey was relatively quick to complete; the median time to take the survey was 17 minutes and 18 seconds for completed responses.

\section{Results}

\subsection{Construct Measurement and Validity}

The research examines the impact of technology on fit with a collaborative writing and editing task. Three variables from the research model (Task-Technology Fit, Perceived Ease of Use, and Perceived Usefulness) are measured and statistically analyzed to understand this impact. Perceived Ease of Use and Perceived Usefulness are measured as single constructs. Task-Technology Fit is indirectly measured as interaction between task characteristics (Knowledge, Planning, and Work) and technology functionality (Dishaw \& Strong, 1999), and are defined as follows:

- Knowledge: Perceived effort in examining and evaluating the work that was done.

- Planning: Perceived effort in determining the work that needed to be done and how to do it.

- Work: The actual completion of work on the project.

- Technology Functionality (Tech): Perceived support of the technology for tasks associated with creating and editing a paper.

The three first constructs were measured based on the subjects' responses to a set of questions on the survey used to collect data. The Technology Functionality construct was not measured independently as it is represented by the tool. The responses for each question that made up the construct were averaged by subject to provide a single construct measurement for the subject. To calculate Task-Technology Fit, the mean for the Technology construct was multiplied by the mean of each of the other three constructs that make up fit: Knowledge, Plan, and Work. The survey items that were used for each construct are included in Appendix A. Although the survey was previously validated, construct reliability was assessed in this research. Cronbach's Alpha is reported in Table 2, and shows that the construct measurements are reasonably reliable.

Table 2. Cronbach's Alpha results showing that the construct measurements are reasonably reliable

\begin{tabular}{ll}
\hline Construct & Cronbach's Alpha \\
\hline Perceived Ease of Use & 0.924 \\
Perceived Usefulness & 0.917 \\
Perceived Support for Coordination & 0.916 \\
Perceived Support for Control & 0.819 \\
Task-Technology Fit: & 1 \\
Knowledge & 0.752 \\
Work & 0.622 \\
Planning & 0.542 \\
Tech & 0.735 \\
Experience & 1 \\
Docs Experience & 0.747 \\
365 Experience & 0.708 \\
Word Experience & 0.878 \\
\hline
\end{tabular}

\subsection{Evaluation of Hypotheses}

As noted above, Office Live changed to Office 365 during one period of data collection. Because there is no way of telling which version the subjects used, that data was eliminated from the study for the hypothesis testing. However, this also provided an opportunity to examine the impact of these changes. This analysis is presented after the results for the hypothesis testing. The hypothesis testing results are examined by grouping hypotheses according to their focus on task-technology fit, experience with the technology, and technology support for coordination and control of the document creation and editing task.

\subsubsection{Evaluation of Task-Technology Fit}

The first set of hypotheses, which focused on the difference between the technologies with respect to the dependent variables, was tested via one-way ANOVA to test for significant differences in the variable means. 
Descriptive statistics for the variables are presented in Figure 5 with the results for Work, Planning, and Knowledge normalized to a 7-point scale. Higher means indicate better fit, usefulness, ease of use, and effort of collaboration. The ANOVA results found statistically significant differences in all the variable means, suggesting that there is a difference in the three technologies tested in terms of Task-Technology Fit, perceived ease of use and usefulness, and perceived support for coordination and control.

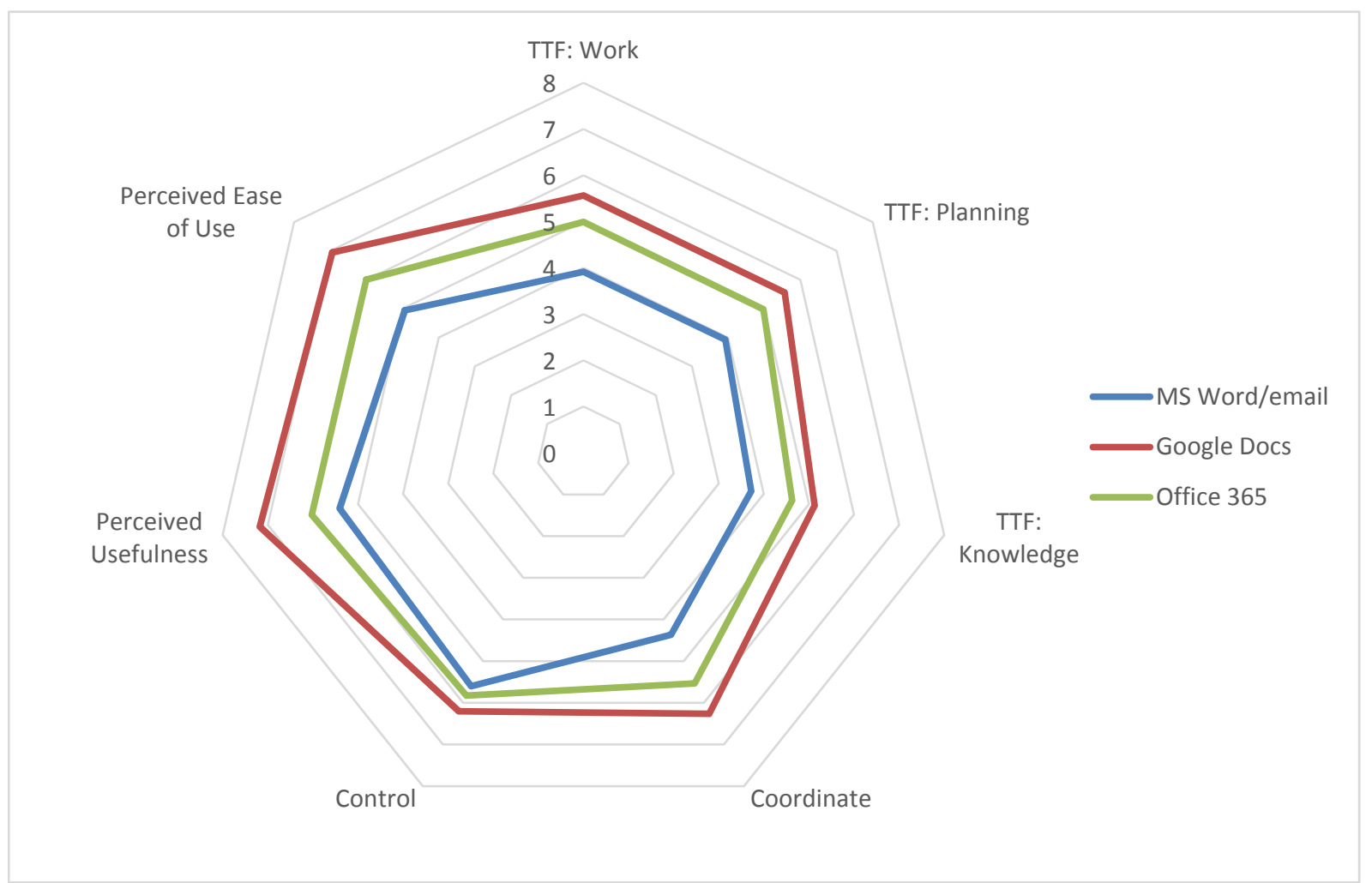

Figure 5. Means for the Task-Technology Fit variables (Work, Planning, and Knowledge), as well as Perceived Ease of Use, Perceived Usefulness, Control, and Coordinate. Higher values (outer rings) indicate better fit, usefulness, ease of use, and effort of collaboration

Hypotheses 1, 2, and 3 postulated that there was no difference between the three technologies with respect to Task-Technology Fit (made up of Work, Planning, and Knowledge), Perceived Ease of Use, and Perceived Usefulness. Our analysis found that Google Docs had a statistically significant higher mean than that of Office 365 , and Office 365 had statistically significant higher means $(p=0.000)$ than Word/email, on all these variables, except for the TTF variable Knowledge, where the difference wasn't significant. Thus, Hypothesis 1 is largely rejected, and Hypotheses 2 and 3 are completely rejected.

We found similar results with regards to Hypothesis 4, which postulated that there was no difference in the perceived support for coordination and control between the three technologies. Our analysis found a similar pattern with Google Docs scoring higher than Office 365, which scores higher than Word/email. The results are statistically significant $(p=0.000)$ for all three technologies for Coordination. However, for Control, while Google Docs was found to better support control $(p=0.020)$, we found no statistical difference in this variable between Office 365 and Word/email, indicating neither performed better than the other in perceived support of control of the task. Hypothesis 4 is partially rejected.

In sum, and as is clearly visible from Figure 5, Google Docs performed better than Office 365, which in turn performed better than Word on all variables.

\subsubsection{Evaluation of the Impact of Tool Experience}

The second set of hypotheses investigated whether or not there was a difference in user experience with the technologies and whether or not experience was correlated with perceptions of the technologies' ease of use and usefulness and Task-Technology Fit. First, the mean value for reported experience was tested to determine if 
there was a difference in experience (Table 3). The result shows that subjects had the most experience with Word, followed by Google Docs, and finally Office 365 . The differences with regards to experience are statistically significant, and we can thus reject Hypothesis 5.

Table 3. One-sample statistics

\begin{tabular}{llllll}
\hline & $\mathrm{N}$ & Mean & Std. Deviation & Std. Error Mean & $\mathrm{p}$ (2-tailed) \\
\hline 365 Experience & 148 & 5.0270 & 2.42421 & .19927 & .000 \\
Docs Experience & 148 & 8.9595 & 2.26442 & .18613 & .000 \\
Word Experience & 148 & 12.1622 & 1.45244 & .11939 & .000 \\
\hline
\end{tabular}

In order to evaluate Hypotheses 6, 7, and 8, we calculated the Pearson Correlation (Table 4). There is a correlation between Tool Experience and Perceived Ease of Use for Word, but there is no correlation for Google Docs and Office Live/365. Hypothesis 6 is partially rejected. There is a correlation between Tool Experience and Perceived Usefulness for both Word and Google Docs, but there is no correlation for Office Live/365. Hypothesis 7 is partially rejected. There is a correlation between Tool Experience and Task-Technology Fit for Office Live/365, but there is no correlation for Word and Google Docs. Hypothesis 8 is partially rejected. However, although significant, these correlations are small.

Table 4. Correlations

\begin{tabular}{|c|c|c|c|c|c|c|}
\hline & & $\begin{array}{l}\text { Perceived } \\
\text { Usefulness }\end{array}$ & $\begin{array}{l}\text { Perceived Ease } \\
\text { of Use }\end{array}$ & Work & Planning & Knowledge \\
\hline \multirow{3}{*}{$\begin{array}{l}\text { Docs } \\
\text { Experience }\end{array}$} & Pearson Correlation & $.137^{*}$ & .113 & .053 & .109 & .054 \\
\hline & Sig. (2-tailed) & .041 & .093 & .433 & .103 & .425 \\
\hline & $\mathrm{N}$ & 223 & 223 & 223 & 223 & 223 \\
\hline \multirow{3}{*}{$\begin{array}{l}\text { Word } \\
\text { Experience }\end{array}$} & Pearson Correlation & $.253^{* *}$ & $.205^{* *}$ & .015 & .046 & .000 \\
\hline & Sig. (2-tailed) & .000 & .002 & .827 & .497 & .997 \\
\hline & $\mathrm{N}$ & 222 & 222 & 222 & 222 & 222 \\
\hline \multirow{3}{*}{$\begin{array}{l}365 \\
\text { Experience }\end{array}$} & Pearson Correlation & .118 & .112 & $.157^{*}$ & $.165^{*}$ & $.145^{*}$ \\
\hline & Sig. (2-tailed) & .078 & .094 & .019 & .014 & .031 \\
\hline & $\mathrm{N}$ & 223 & 223 & 223 & 223 & 223 \\
\hline
\end{tabular}

Note. **. Correlation is significant at the 0.01 level (2-tailed). *. Correlation is significant at the 0.05 level (2-tailed).

To further examine the impact of experience, we performed an ANOVA to determine if there was any difference in experience with the technology between the subjects assigned to different technologies (Figure 6). We determined that there was no significant difference in experience with Google Docs or MS Word for any of the subject groups. However, the subjects assigned to use Office 365 had more experience with Office $365(p=0.000)$ than the subjects assigned to other groups. 


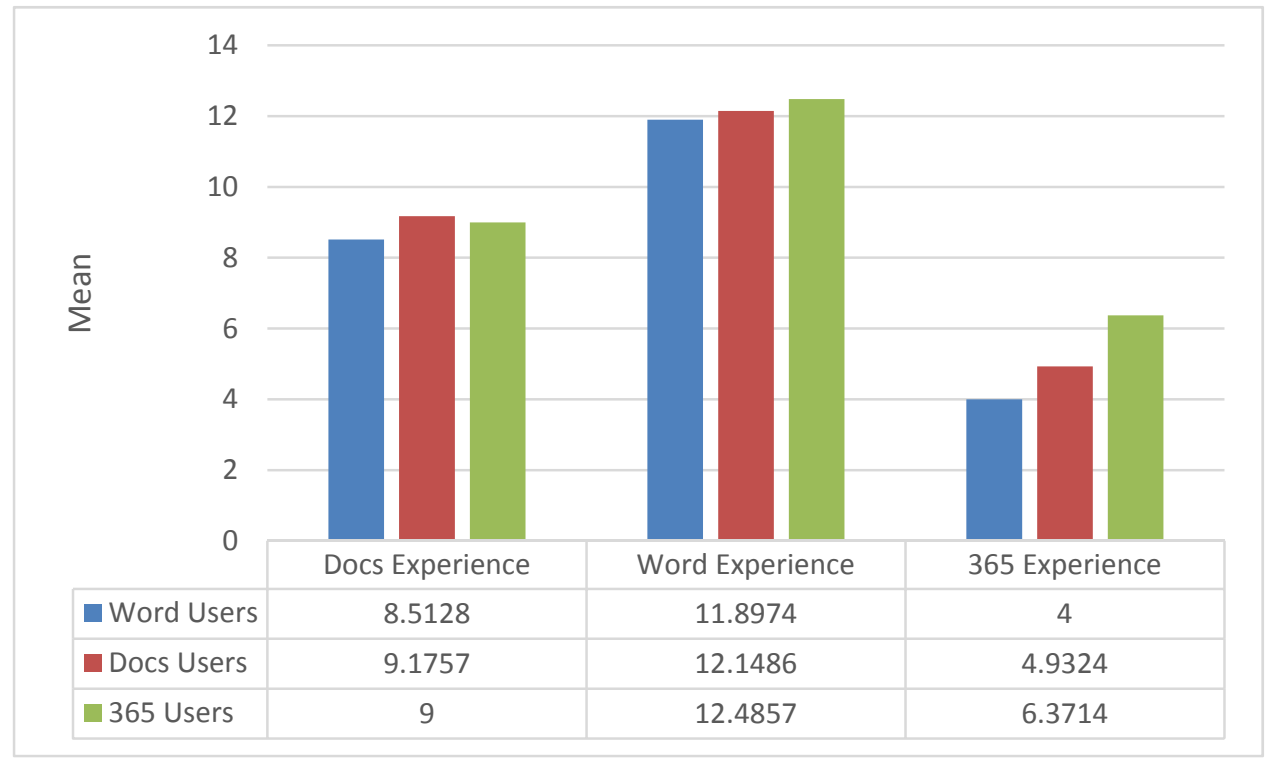

Figure 6. Experience of each user group with each of the three technologies

The following examine if there is a correlation between Perceived Ease of Use and Perceived Usefulness and Experience with a technology for each treatment. For subjects that used Word or Office 365, their experience with any of the technologies had no impact on their Perceived Ease of Use or Perceived Usefulness of the technology they actually used. However, for subjects that used Google Docs, experience with Word was significantly correlated with their ratings of Perceived Ease of Use and Perceived Usefulness of Google Docs (Table 5). In other words, it appears that if they were more experienced with Word, they found Google Docs easier to use and more useful.

Table 5. Experience and pearson correlation for google docs users

\begin{tabular}{llll}
\hline & & $\begin{array}{l}\text { Perceived } \\
\text { Usefulness }\end{array}$ & $\begin{array}{l}\text { Perceived Ease of } \\
\text { Use }\end{array}$ \\
\hline Docs Experience & Pearson Correlation & .144 & .084 \\
& Sig. (2-tailed) & .221 & .476 \\
& $\mathrm{~N}$ & 74 & 74 \\
Word Experience & Pearson Correlation & $.338^{* *}$ & $.272^{*}$ \\
& Sig. (2-tailed) & .003 & .019 \\
& $\mathrm{~N}$ & 74 & 74 \\
365 Experience & Pearson Correlation & .055 & -.056 \\
& Sig. (2-tailed) & .642 & .633 \\
& $\mathrm{~N}$ & 74 & 74 \\
\hline
\end{tabular}

Taken together, the statistical analysis appears to suggest that experience with the technology is having some impact on the subject's evaluation of how easy to use and useful a technology is. However, this impact is not always as expected. In some cases, experience with a technology impacts the technology itself. In other cases, experience with a technology impacts the perception of another technology's usefulness and ease of use.

\subsubsection{Evaluation of the Impact of Technology Support for Coordination and Control}

The final set of hypotheses (H9-H14) focuses on the impact of the technologies' perceived support of coordination and control of the task on Perceived Usefulness, Ease of Use, and Task-Technology Fit. These hypotheses were tested with a Pearson Correlation (Table 6). The results show that there is significant correlation between support for Coordination and Control and Perceived Usefulness, Perceived Ease of Use, and all the TTF variables. Hypotheses 9 through 14 are rejected. 
Table 6. Pearson correlation for coordination and control

\begin{tabular}{llll}
\hline & & Coordination & Control \\
\hline Perceived Usefulness & Pearson Correlation & $.457^{* *}$ & $.360^{* *}$ \\
& Sig. (2-tailed) & .000 & .000 \\
& $\mathrm{~N}$ & 160 & 160 \\
Perceived Ease of Use & Pearson Correlation & $.494^{* *}$ & $.389^{* *}$ \\
& Sig. (2-tailed) & .000 & .000 \\
& $\mathrm{~N}$ & 160 & 160 \\
TTF: Work & Pearson Correlation & $.501^{* *}$ & $.435^{* *}$ \\
& Sig. (2-tailed) & .000 & .000 \\
& $\mathrm{~N}$ & 160 & 160 \\
TTF: Planning & Pearson Correlation & $.476^{* *}$ & $.367^{* *}$ \\
& Sig. (2-tailed) & .000 & .000 \\
& $\mathrm{~N}$ & 160 & 160 \\
TTF: Knowledge & Pearson Correlation & $.525^{* *}$ & $.434^{* *}$ \\
& Sig. (2-tailed) & .000 & .000 \\
& $\mathrm{~N}$ & 160 & 160 \\
\hline
\end{tabular}

**. Correlation is significant at the 0.01 level (2-tailed).

\subsection{Evaluation of the Impact of Change in Technology Function}

During analysis, we noted that, over time, the values for the TTF variables and Perceived Ease of Use and Perceived Usefulness increased for Google Docs and Office Live/365, but decreased for Word/email. This was interesting because over the time period of the study, the Word functionality stayed relatively stable, Google Docs was continually enhanced with additional functionality, and Office Live was re-released as Office 365 in Fall 2013. This invalidated data collection for that semester because there was no way to determine if subjects used Live or Office 365. However, this presented a clear point in time where the technologies diverged. To examine if these changes made an impact, we tested each technology designating the technology before Fall 2013 as one version and after Fall 2013 as a second version.

Word/email got statistically significantly worse $(p=0.000)$ over time on all outcome variables except control (Figure 7). In contrast, Google Docs became progressively better $(p=0.000)$ over time for all outcome variables except Coordinate (Figure 8). Coordinate became better, but it's not statistically significant. Office Live/365 is mixed. It became better over time ( $p$ values ranging from 0.001 to 0.011 ) on all outcome measures except Coordinate and Control, which stayed relatively unchanged (Figure 9). In each of these three graphs, higher values indicate better performance- thus, the outer rings indicate that the technology performed better than the inner rings. 


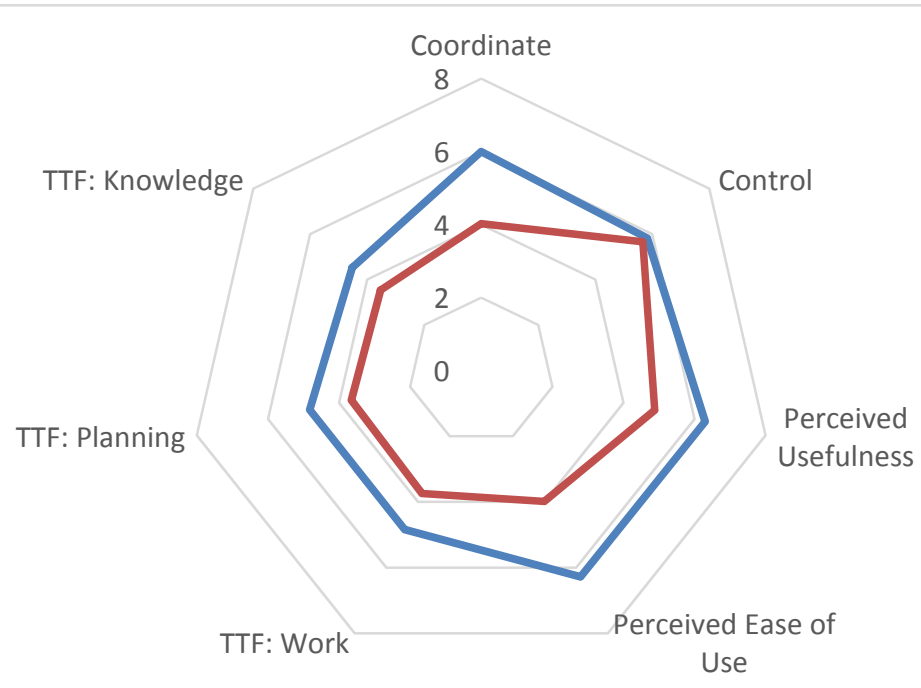

Before Fall 2013

After Fall 2013

Figure 7. Word/Email measured over time

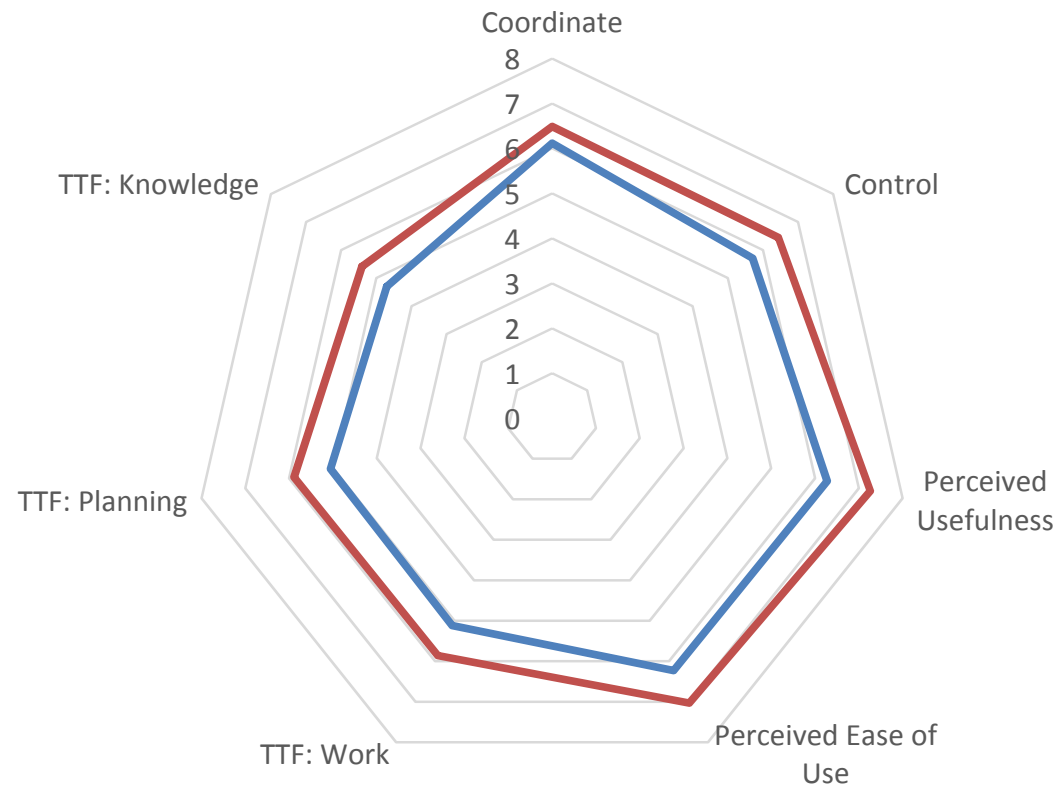

Before Fall 2013

After Fall 2013

Figure 8. Google Docs measured over time 


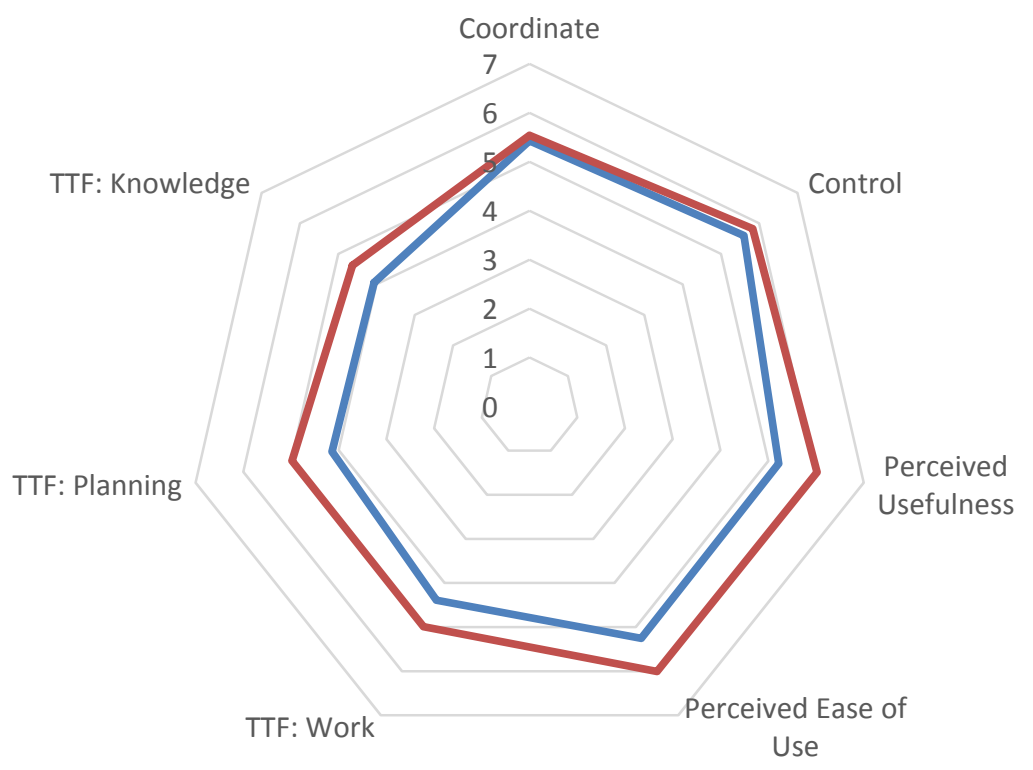

Figure 9. Office Live/365 measured over time

\section{Discussion}

In one sense, the results are not surprising. The TAM/TTF model predicts that Tool Experience and Task-Technology fit impact Perceived Ease of Use and Perceived Usefulness which is what we found. The model also predicts that Tool Functionality and Task Characteristics impact Task-Technology Fit. During the period of our studies, Task Characteristics have been held constant and the MS Word/email technology has been relatively stable. Therefore, the perception of Fit for this tool should have been relatively stable. However, it declined. It appears that the assessment of fit relies not only on these characteristics, but also on the fit of other tools. Still, Tool Functionality does have a significant impact, as evidenced by the difference in the evaluation of Fit for Office 365 after the Fall 2013 revision. One significant difference between the two versions is the elimination of the confusing Save/Refresh button, which eliminated the "Uncanny Valley" phenomenon that we identified in our previous study (Dishaw et al., 2013) and made the tool better match the mental model of the user.

The perception that a tool is less useful in contrast to other known available tools is not surprising. Prior to having experience with tools that fit the collaborative editing task better, MS Word/email was rated as relatively useful because subjects knew how to use it and it represented the best way to accomplish the task. However, as other tools such as Google Docs became better tools, and subjects got experience with them, they realize that exchanging documents via email is not the best way to perform the task. Thus, Task-Technology Fit falls and the Perceived Usefulness of the technology also falls. This suggests that suppliers of a technology must constantly assess the current state of their competitors to ensure that their tools currently match the task as well as other tools. Similarly, IT departments and others who adopt technologies on behalf of large groups of users must be aware of how non-adopted technologies change, and consider switching to new technologies, even if both the tasks and adopted technologies have stayed constant.

As a result of this study, we propose that experience with other tools be added to the TAM/TTF model. It appears that a users' experience with other tools designed to support the same task can impact their perception of the fit of a specific tool. Experience with the specific tool in question is not the only experiential factor that impacts TTF. Figure 10 shows the proposed research model based on the influence of experience with other tools to perform the same task. 


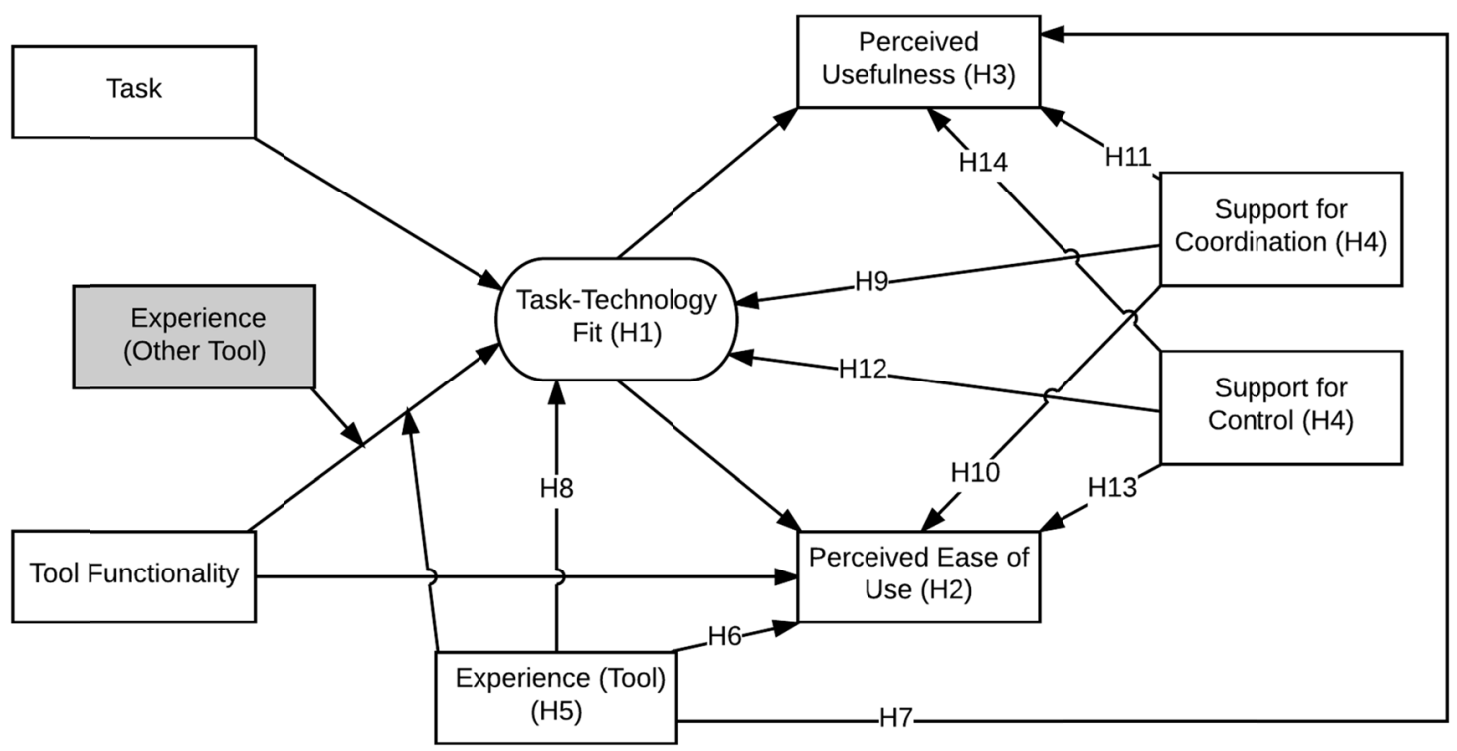

Figure 10. Proposed research model including experience with other tools

Improving products to match or better the fit of the technology with the task is not without its dangers, as evidenced by the Office Live problems. Suppliers of a technology may wish to leverage users' experience and understanding of their technology in new versions by keeping the interface similar. However, if the new functionality assigned to an existing interface element differs too greatly from the past function, this may backfire. As always, significant testing of any new product should be conducted prior to release.

The decrease in Perceived Ease of Use score for MS Word/email at first blush does not appear to make sense. It is essentially the same product, and users have significant experience with it. How did it get harder to use (or was perceived as such)? One explanation is that as other tools changed, the users' mental model of the task changed with them. Exchanging documents via email no longer fit their model of the task, and thus it appeared more difficult. Another potential explanation is that the process of sending the document and coordinating changes is just considered a hassle, especially when it can be stored more easily in a location accessible to all editors, making the sending of documents seem to be harder to use. Another explanation could be as simple as that subjects were upset at being forced to use a tool they believe to be inferior, causing them to have a negative mindset when filling out the survey.

Experience matters...to a point. The subjects of this study reported significantly higher experience with MS Word than the other technologies. However, MS Word/email performed significantly poorer than the other two technologies. It appears that without Tool Experience, fit is hard to assess. Additionally, experience with tools that have a better Task-Technology Fit lower the assessment of the fit of tools previously thought to have a good Task-Technology Fit. Although not analyzed statistically, the TTF variables and Perceived Ease of Use and Perceived Usefulness measures for MS Word/email in the first of our studies (Dishaw et al., 2011) are nearly the same as the Google Docs measures on these variables in this study. Additionally, those measures are much lower for MS Word/email in this study than they were in the first study.

The postulated "Compensatory Factor" in the previous study also appears to be tentatively supported. The Perceived Support of Coordination and Control is significantly correlated with Perceived Ease of Use, Perceived Usefulness and the TTF variables. This suggests that if one technology provides better support of one of these and the other provides better support for the other, the resulting overall perception of the tool might be similar. Over the past several years, the Google Docs editor has improved and become richer. Given that it already supported collaboration better than MS Word/email, this improvement significantly impacted its performance. However, no direct measures of perceptions of the two editors were collected in any study.

\subsection{Implications for Pedagogy}

Different tools have a different fit with a task. Furthermore, this fit can change as other technologies advance. Educators should continually re-assess the tools they assign for use in assignments. A tool that once was perceived as adequate or good may now lead to negative reactions by students. Although this may not lead to poorer outcomes for the students, it may lead to negative perceptions of the course or topic. If an educator is 
introducing a new tool for a task, care should be taken to train students adequately and emphasize how the new technology better matches the task than an older technology that they may have more experience with. Whereas in 2009 it was perfectly valid to ask groups of students to complete a collaborative editing task using Word and email, by 2013 the same project likely should be completed using Google Docs or Office 365.

\subsection{Implications and Directions for Future Research}

Although the findings of this study are intriguing, they are by no means definitive. Significant questions remain, such as does Task-Technology Fit really change? This study found that MS Word/email measures of fit significantly declined over the study period. Is this a measurement problem caused by the forced use of the technology? Or, is it due to a change in the mental model of the task held by the subjects of the study? If the mental model of the task changed, did new technology change it? To what extent? Does experience with a technology impact understanding of the technology's fit with a task? If so, how much training or experience with a technology is required to adequately assess fit? How should suppliers of a technology assess the fit of their product as well as those of their competitors? How should IT departments and educators continuously assess tools already adopted against new offerings on the market?

\subsection{Limitations}

Several limitations may impact the generalizability of this study. First, the use of small, three-person groups of students may favor one type of collaborative process over another which in turn favored the tool that best supported that process. Second, student subjects may have characteristics that differ markedly from business professionals thus limiting the applicability of the findings to the business world. Third, the task of document creation and editing may not be applicable to other types of collaborative work. A final confounding factor is the relative availability of Google Docs versus Office 365. Google Docs is used in the school districts surrounding our University and is available to all students at the University. This may mean that Office 365 is at a disadvantage. The participants in this study reported significantly less experience with Office 365 than the other two technologies. However, for those subjects forced to use it, their usefulness ranking of it increased, and their usefulness ranking of Google Docs decreased. This suggests that if participants had as much experience with Office 365 as they had with the other two technologies, it would have scored better on the TAM/TTF measures.

\section{Conclusion}

These results suggest that how, and how well, a collaborative technology implements certain functions may have a significant impact on the effectiveness of the tool in supporting the collaborative task. First, it appears that the tool must have an interface that is powerful with which the user has some experience. Second, the distinguishing factor can be the support for distributed collaboration provided. Finally, it is very important that the mechanics of how the tool enables the collaboration matches the user's mental model of how it is doing it. Our studies suggest that Google Docs outperforms Office 365, which in turn outperforms MS Word/email, which is likely due to tool experience in the case of Google Docs versus Office 365 and superior Task-Technology Fit for Google Docs and Office 365 to MS Word/email.

The perception of a tool also is influenced by experience with other tools. During a period where the functionality of Word stayed constant, it came to be perceived as less useful for the task, while other tools improved their functionality and came to be perceived as more useful. This suggests that suppliers and adopters of a technology must constantly assess the capabilities supplied by competing products and the match between those capabilities and the task the technology is designed to support.

\section{References}

Brodahl, C., Hadjerrouit, S., \& Hansen, N. K. (2011). Collaborative writing with web 2.0 technologies: education students' perceptions. IIP73-IIP103. Retrieved from http://brage.bibsys.no/xmlui/handle/11250/138167

Davis, F. D., Bagozzi, R. P., \& Warshaw, P. R. (1992). Extrinsic and Intrinsic Motivation to Use Computers in the Workplace. Journal of Applied Social Psychology, 22(14), 1111-1132. https://doi.org/10.1111/j.1559-1816.1992.tb00945.x

Dishaw, M. T., \& Strong, D. (1999). Extending the technology acceptance model with task-technology fit constructs. Information \& Management, 36(1), 9-21. https://doi.org/10.1016/S0378-7206(98)00101-3

Dishaw, M. T., \& Strong, D. M. (2003). The effect of task and tool experience on maintenance CASE tool usage. Information Resources Management Journal, 16(3), 1-16. https://doi.org/10.4018/irmj.2003070101

Dishaw, M. T., Eierman, M. A., Iversen, J. H., \& Philip, G. C. (2011). Wiki or Word? Evaluating tools for collaborative writing and editing. Journal of Information Systems Education, 22(1), 43-54. 
Dishaw, M. T., Eierman, M. A., Iversen, J. H., \& Philip, G. C. (2013). An Examination of the Characteristics Impacting Collaborative Tool Efficacy: The Uncanny Valley of Collaborative Tools. Journal of Information Technology Education: Research, 12, 301-325. https://doi.org/10.28945/1899

Frost \& Sullivan. (2006). Meetings around the world: The impact of collaboration on business performance (A Frost \& Sullivan White Paper sponsored by Verizon Business and Microsoft). Verizon Business. Retrieved from http://www.verizonbusiness.com/us/resources/conferencing/impactcollab.pdf

Garza, V., \& Kock, N. (2007). Designing the user interface: Strategies for effective human-computer interaction. International Journal of E-Collaboration, 3(2), 53.

Goodhue, D. L., \& Thompson, R. L. (1995). Task-technology fit and individual performance. MIS Quarterly, 213-236. https://doi.org/10.2307/249689

Hertel, G., Geister, S., \& Konradt, U. (2005). Managing virtual teams: A review of current empirical research. Human Resource Management Review, 15(1), 69-95. https://doi.org/10.1016/j.hrmr.2005.01.002

Kock, N. (2005). What is e-collaboration? International Journal of E-Collaboration, 1(1), i-vii.

Mori, M. (1970). The Uncanny Valley. Energy, 7(4), 33-35.

Nosek, J. T., \& McManus, M. (2008). Collaboration challenges: bridging the IT support gap. Information Systems Management, 25(1), 3-7. https://doi.org/10.1080/10580530701777081

Parker, K. R., \& Chao, J. T. (2007). Wiki as a teaching tool. Interdisciplinary Journal of Knowledge and Learning Objects, 3, 57-72. https://doi.org/10.28945/3131

Rienzo, T., \& Han, B. (2009). Microsoft or Google web 2.0 tools for course management. Journal of Information Systems Education, 20(2), 123-127.

Venkatesh, V., \& Davis, F. D. (2000). A Theoretical Extension of the Technology Acceptance Model: Four Longitudinal Field Studies. Management Science, 46(2), 186-204. https://doi.org/10.1287/mnsc.46.2.186.11926

\section{Appendix A}

\section{Construct Items}

\section{Knowledge Construct Items}

I obtained information about changes to the document from data in the document itself.

I made extensive use of my knowledge of the software with which the document was created.

If I needed information to solve a problem, I knew where to look or who to ask.

I asked someone for technical information about the designated software during this project.

I consulted manuals to obtain information regarding Windows Operating System.

I consulted manuals to obtain information about the software.

I examined the document to obtain clues as to the quality of the paper.

I obtained information about the paper being produced through examining the document.

I learned a great deal about the topic of the paper by mentally processing the information provided in the document.

I frequently consulted the software documentation.

I learned a great deal about the topic by using the designated software tool.

I had to weigh and evaluate a large volume of information about the document I was creating/editing.

I had difficulty deciding which source of information to employ in attempting to solve a particular problem.

Plan Construct Items

I had no difficulty in editing/changing the document.

I did not have difficulty in figuring out how to create/edit the group paper.

I frequently re-evaluated my plan of action with regard to completing the project. 
I had a number of choices to make regarding which source of information to consult in order to solve a particular problem.

I frequently had alternative approaches to writing the document.

Work Construct Items

I frequently made changes to the document in order to get feedback from other group members.

I revised the document.

I often evaluated other group members' changes to the document.

I read the document and made additional changes as a result of my reading.

\section{Coordination Construct Items}

To what extent did the designated software tools supply the following functionality?

Track schedule information for the project.

Track time and resources expended on the project.

Maintain information about project status.

Send information or messages to other individuals.

Exchange information relating to the project with other individuals.

Maintain a record of who is responsible for each part of the project.

Share project data or information with other individuals.

\section{Control Construct Items}

To what extent did the designated software tools supply the following functionality?

I had to observe group conventions during this project.

The group established standards or norms that all group members were expected to follow.

I followed a standard procedure in completing this project.

I fixed "problems" in the project.

I communicated with others so that my work would not negatively impact their work.

I made an effort to ensure that the changes I made in this project would not interfere with other work being done at the same time by others.

I was required/expected to submit my work for review to someone else.

I had to keep another person informed of my work so as to keep my work consistent with another project.

\section{Ease of Use Construct Items}

I found it easy to get the designated software to do what I wanted it to do.

My interaction with the designated software was clear and understandable.

I found the designated software to be flexible to interact with.

I found the designated software easy to use.

\section{Usefulness Construct Items}

Using the designated software enabled me to accomplish my tasks more quickly.

Using the designated software enabled me to improve my performance on this project.

Using the designated software increased my productivity on this project.

Using the designated software enabled me to enhance my effectiveness on this project.

Using the designated software made it easier to complete this project.

I found the designated software useful in this project.

\section{Technology Construct Items}

To what extent did the software environment available to you supply the following functions?

Create and write text. 
Edit existing text.

Share a text document among individuals.

Track changes in the text document.

Identify the source of changes in the text document.

Questions to measure technology experience:

How frequently have you used Google Docs to create or edit documents? (1-7)

How familiar are you with Google Docs? (1-8)

How frequently have you used Microsoft Office Live to create or edit documents? (1-7)

How familiar are you with Microsoft Office Live? (1-8)

How frequently have you used Microsoft Word to create or edit documents? (1-7)

How familiar are you with Microsoft Word? (1-8)

Scale for "How frequently have you used..."

Never

Only a couple of times

Once a month

2-3 times per month

Once a week

2-3 times per week

Daily

Scale for "How familiar are you with ..."

Never heard of them

I have heard of them but don't really know what they are

I know what they are

I know how to use them

I consider myself a proficient user

I consider myself an expert user

I and others consider me an expert

\section{Copyrights}

Copyright for this article is retained by the author(s), with first publication rights granted to the journal.

This is an open-access article distributed under the terms and conditions of the Creative Commons Attribution license (http://creativecommons.org/licenses/by/4.0/). 